\title{
Mechanical Performance of Cementitious Composites by MWCNTs Addition for Structural Applications
}

\author{
Mohd Moonis Zaheer \\ Department of Civil Engineering, Z.H. College of Engineering and Technology, Aligarh Muslim University, \\ Aligarh, India \\ E-mail: mooniszaheer@rediffmail.com
}

Received: 20 September 2019; Accepted: 21 October 2019; Available online: 5 February 2020

\begin{abstract}
This paper presents the investigation on the behaviour of a prism reinforced with multi walled carbon nanotubes (MWCNTs) to study mainly the strength and durability aspects for structural applications. Prisms were made by varying the MWCNT content from 0.1 to $0.5 \%$ by weight of cement. Ultrasonic energy was employed to disperse carbon nano tubes (CNTs) in water. For evaluating mechanical property such as load-deflection, tests were performed on CNT admixed prisms under flexure. The outcomes were then compared with plain mortar prisms. An attempt has also been made to explore the optimum concentration of MWCNT additions that will give ideal performance with respect to mechanical and durability properties. Flexural and compressive strength is enhanced by $25 \%$ and $19 \%$, respectively compared to control prisms at 28 days when CNT was used in the cementitious matrix. Both porosity and water absorption are reduced by about $25 \%$ at 28 days. Based on the parametric study, a tentative optimum CNT concentration ( $0.3 \%$ by weight of cement) has been proposed. SEM images shows perfect crack bridging mechanism; several of the CNTs were shown as crack arrestor across the fine cracks along with some CNTs breakage.
\end{abstract}

Keywords: Carbon nano tubes; Nano materials; Flexural strength; Load-deflection; Porosity; Water absorption.

\section{Introduction}

In the past decade, nanotechnology research can be thought as the most encouraging area in the field of material science. Of late, many types of carbon nano filaments have raised attention of research community in construction industry due to their unique chemical, mechanical and electrical properties and remarkable performance in reinforcing cementitious materials [1,2]. A high aspect ratio and exceptionally high strength of $60 \mathrm{GPa}$ is the characteristic of CNTs [3]. It also has very high elastic modulus around 1 TPa and ductility of 12\% [4]. Such exceptional properties confirm the potential of CNTs as an excellent reinforcing agent within the cement matrix. Therefore, exploration on developing suitable nanotechnology with CNTs in mortar is of significant interest in the past decade. Mechanical properties of mortar, particularly flexural and compressive strength, depends on mass transfer and microstructure at nano level [5]. Moreover, it is established that hydration products can be modified through nanotechnology. Addition of CNTs can, therefore, enhance strength properties apart from improved density of composites, as well as lower water absorption values.

Whereas extensive studies on carbon nano tubes has been focused on their integration in polymers, less consideration has been given on using nano tubes in cement mortar. Further, limited research of nano tube effectiveness in augmenting load deflection characteristics or reduced porosity and water absorption has been done. Within recent past, several researchers obtained improved mechanical properties of cementitious composites by incorporating CNTs. Li et al.[6] investigated both treated and untreated MWCNTs in cementitious composites and reported that strength properties of composites with treated nano tunes were marginally higher in comparison to untreated counterparts. Manzur and Yazdani [3] investigated the effect of different sizes and dosage rates of MWCNTs on the properties of cement composites, and recommended a CNT concentration between $0.1-0.3 \%$. In another study, Al-Rub et al. [7] studied the influence of CNT aspect ratio on the mechanical properties of composites. It was found that 28 days strength in flexure with short and long CNTs was improved by $269 \%$ and $65 \%$, respectively. Hallad et al. [8] obtained $88 \%$ increase in flexural strength by adding both carbon micro fibers and MWCNTs as compared to the control samples. Manzur and Yazdani [9] investigated the effect of two different MWCNT sizes on compressive strength and found $15-25 \%$ increase in compressive strength. Yazdani and Mohanam [10] investigated the effect of short CNTs and long carbon nano fibers (CNFs) on the mechanical strengths of cement mortars. The results showed an increase of $50 \%$ and $150 \%$ in flexure and compressive strengths compared to plain mortar. Recently, Mohsen et al. [11] investigated the ideal CNT content for improving 
mechanical strength of cementitious composites and showed that $0.25 \%$ CNT content gave optimum results. Influence of CNTs on various properties like physical, mechanical, electrical and piezoresistive sensitivity of cementitious materials was critically presented by Rashad [12]. In one of the studies, exceptional reinforcing behaviour of MWCNTs were demonstrated by the improved compressive strength and reduced water absorption values [13].

Permeability and mechanical properties of cementitious composites with fly ash and silica fume was investigated by Sadrmomtazi et al. [14] and showed improvement in strength and reduction in permeability of concrete. Fracture behaviour and pore structure of concrete with metakaolin was studied by Akcay et al. [15]. It was found that increasing the amount of metakaolin reduced the porosity for the prisms with low water to binder ratios. Strength and durability study on cement mortar with nano silica and nano metakaolin was investigated by Ashok et al. [16]. Water absorption and chloride penetration tests showed that mortar added with nano silica and nano metakaolin have better permeability resistance. Durability of mortar admixed with CNT and nano silica was investigated by Lee et al. [17] and showed increased compressive strength by $12-76 \%$ apart from enhanced corrosion resistance properties. Durability of MWCNT reinforced concrete was studied by Carriço et al. [18] and found that addition of $0.05-0.1 \%$ CNTs by weight of cement improved the mechanical strength and durability properties by $21 \%$ and $25 \%$, respectively. Combined effect of micro silica (MS) and nano silica (NS) on the durability of mortar was investigated by Li et al. [19] and showed that combined addition of MS and NS offers additive effects in chloride resistance. In one of the study, compressive strength of mortar was found to decrease by enhanced porosity of the composites [20]. In a recent paper, Lee et al. [17] investigated performance of cement mortar admixed with nanosilica and showed that $1 \%$ nanosilica and $0.03 \%$ CNT performed better in terms of reduced water absorption characteristics. A comprehensive review summarizing the current knowledge of the microstructure, strength and durability of cementitious materials by incorporating various types of nanomaterials was presented by Paul et al. [21]. In another recent review paper, Shi et al. [22] presented state-of-the art progress on CNT/CNFs modified cementitious composites. The paper highlights various aspects including durability, mechanical and deformation properties apart from thermal and electrical conductivities. While most of the research till date was conducted on durability of concrete admixed with different nano materials. However, properties such as load deflection characteristics and durability of mortar, particularly with CNTs has not been addressed thoroughly, making the present study novel. It is, therefore, imperative to confirm thoroughly the effect of parameters such as nanotube content and curing period on the load deflection and durability properties of CNT composites in order to accomplish better results. In one of the recent studies, Zaheer et al. (2019) investigated mechanical properties of mortar added with two types of CNTs and showed that a CNT concentration of $0.3 \%$ give optimum results for both type of MWCNTs [14].

With this goal in mind, an effort has been made in this study to compare the strengths and load deflection characteristics of flexural prisms added with CNTs to highlight its usefulness as an additive in cement mortar. For uniform dispersion of CNTs in the matrix, ultrasonic energy along with polycarboxylate based superplastisizer was utilized. To study the load deflection characteristics of prisms, three-point flexural bending tests were conducted after curing periods of 7, 14, and 28 days. Durability properties such as density, porosity and water absorption are also determined in order to get insight of material effectiveness. To the authors' understanding, the present study represents only few studies to date that presents experimental data for the stated properties particularly at various curing periods. After the flexural testing, the samples were cut from the ends to the size of cubes $40 \mathrm{~mm} \times 40 \mathrm{~mm} \times 40 \mathrm{~mm}$ from the uncracked portion of the sample for compressive strength, density, porosity and water absorption tests. Five dosage rates of $0.1 \%, 0.2 \%, 0.3 \%, 0.4 \%$ and $0.5 \%$ by weight of cement were used to prepare the prisms. Control samples were also made for comparisons. High-resolution electron microscopy was performed to substantiate the outcomes of the CNT admixed mortar with microstructure at the fractured surfaces.

\section{Experimental work}

\subsection{Materials}

OPC 43-grade (Ultra Tech) and standard sand (0-4.75 mm) meeting the requirements of IS: 650-1991 supplied by Tamil Nadu Minerals Ltd., Chennai were used in the study. The sieve analysis and physical properties of fine aggregates are reported in Table 1. MWCNTs manufactured by Ad-Nano Technologies Pvt. Ltd, Karnataka were used as procured in casting CNT composites. Catalytic Chemical Vapour Deposition (CCVD) process was used to produce these CNTs. Fig. 1 shows the Video photograph and SEM image of CNT used in the present study. The physical properties of CNTs as supplied by the manufacturing company are shown in Table 2. A polycarboxylate based superplastisizer, supplied by Chemcon Tecsys, trade name “CONXL-PCE DM 09"' was used to help in uniform distribution of CNTs in water. 
Table 1. Sieve analysis and physical properties of fine aggregates

\begin{tabular}{ll}
\hline Sieve size (mm) & Fine aggregate (\% passing) \\
\hline 12.5 & 100 \\
9.5 & 100 \\
4.75 & 96.23 \\
2.36 & 73.65 \\
1.18 & 51.23 \\
0.6 & 42.48 \\
0.3 & 14.12 \\
0.15 & 2.83 \\
0.075 & 0 \\
Physical properties & \\
Bulk density $\left(\mathrm{kg} / \mathrm{m}^{3}\right)$ & 1452 \\
Specific gravity & 2.58 \\
Fineness modulus & 2.69 \\
\hline
\end{tabular}

Table 2. Physical properties of MWCNT

\begin{tabular}{ll}
\hline Physical properties & Value \\
\hline Colour & Black \\
Purity $(\%)$ & $>99$ \\
Average Outer Diameter $(\mathrm{nm})$ & $10-20$ \\
Average Length $(\mu \mathrm{m})$ & $1-5$ \\
Amorphous carbon $(\%)$ & $<1$ \\
Surface Area $\left(\mathrm{m}^{2} / \mathrm{g}\right)$ & 370 \\
Average aspect ratio & 200 \\
\hline
\end{tabular}

\subsection{Dispersion of MWCNTs}

Separate batches for CNTs were prepared at five different percentages ( 0.1 through $0.5 \mathrm{wt} . \%$ of cement). For all the prisms, water to cement (w/c) ratio was kept as 0.5 . For each batch, three replicates were prepared and tested after curing periods of 7, 14, and 28 days. The mean value as well as standard error of the mean for the specimen were computed after respective curing periods. Different techniques were used by various researchers for dispersion of MWCNTs, however the sonication technique being most commonly used. In this study, measured quantity of MWCNTs was first mixed with mixture of water and superplastisizer $(0.4 \%$ of SP by weight of cement was added to water). Bath sonicator was employed for 30 minutes to achieve uniform dispersion of CNTs in water. However, as the research of using nanomaterials in concrete/mortar advances, these are now incorporated in the cement itself in few countries during its manufacturing process. Thus eliminating the sonication process. Although, this technique is not well advance, but researchers are hopeful to break this barrier and we get nano modified cement in near future.

The various stages of sonication are shown in Fig. 2 (a)-(d). Before the application of CNTs dispersed water in the mix, three trials were made with regards to sonication time (10 min, 20 min and $30 \mathrm{~min}$ ), respectively. The resulting dispersed CNT solution was filled in test tubes to assess qualitatively its stability. The colour of dispersed solution was observed for next 8 hours. It was revealed that for 30 min sonication time, CNTs in the test tube remains stable and did not settle down indicating effective and uniform dispersion of CNTs. Therefore, $30 \mathrm{~min}$ sonication time was adopted to prepare all mixes.

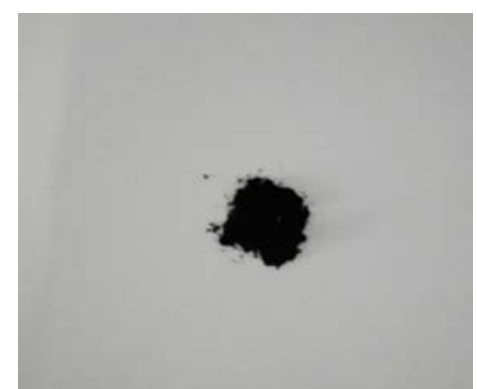

(a) CNT

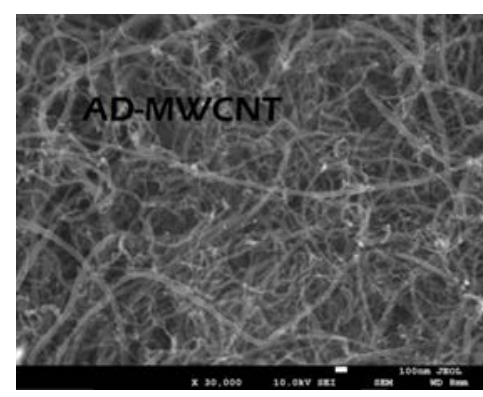

(b) SEM image

Fig. 1. Photographs of CNT under (a) video camera, (b) Scanning electron microscope (SEM) 


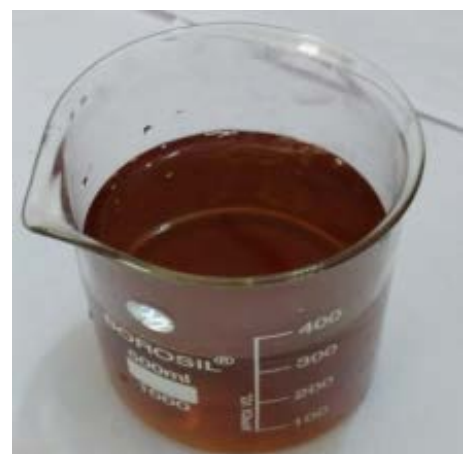

(a) Mixing water with super plasticizer

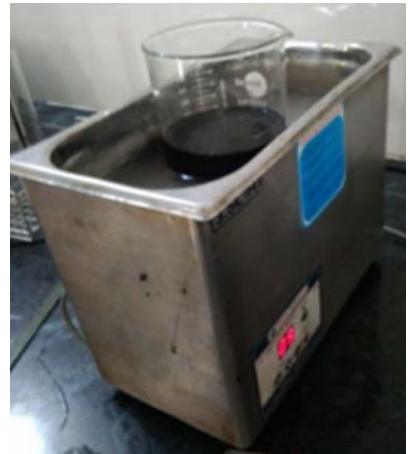

(c) Sonication for dispersion of MWCNT

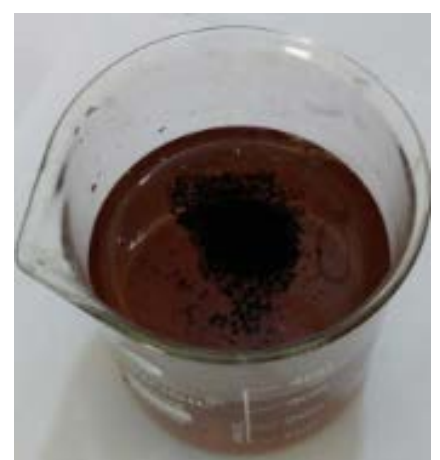

(b) Mixing water with super plasticizer and MWCNT

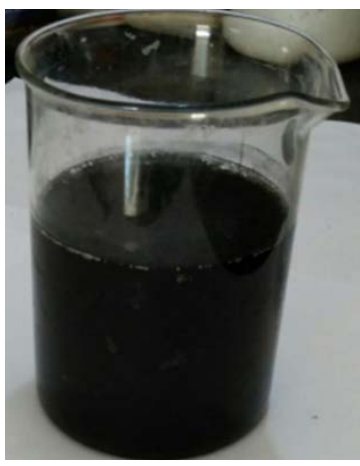

(d) Sonicated water after 30 minutes of sonication

Fig. 2. Different stages of sonication

\subsection{Mixing and sample preparation}

After completion of sonication process, required quantity of sonicated water with a water to cement ratio of 0.5 was poured into the cement sand mixture (1:3). The resulting mixture were then mixed together for $7 \mathrm{~min}$ in a multispeed planetary blender. The mix proportions are shown in Table 3. The moulds conforming to IS: 100781982 was used to prepare the prisms. Prisms were cast by pouring mixture into the moulds of size $160 \mathrm{~mm} \times 40$ $\mathrm{mm} \times 40 \mathrm{~mm}$. Various stages from casting to testing of specimens are shown in Fig. 3 . The moulds were lightly oiled inside before use. The samples were kept in molds under moist condition for $24 \mathrm{~h}$, and finally immersed in water for flexural strength tests after 7, 14 and 28 days. Control prisms were also prepared using the same procedure.

Table 3. Details of the test prisms

\begin{tabular}{llll}
\hline $\begin{array}{l}\text { Specimen } \\
\text { constitution }\end{array}$ & $\begin{array}{l}\text { CNT (\% wt. of } \\
\text { cement ) }\end{array}$ & $\begin{array}{l}\text { Superplastisizer (\% wt. of } \\
\text { cement) }\end{array}$ & Sonication time (min.) \\
\hline Control specimen & 0.0 & 0.4 & 0 \\
$0.1 \%$ CNT & 0.1 & 0.4 & 30 \\
$0.2 \%$ CNT & 0.2 & 0.4 & 30 \\
$0.3 \%$ CNT & 0.3 & 0.4 & 30 \\
$0.4 \%$ CNT & 0.4 & 0.4 & 30 \\
$0.5 \%$ CNT & 0.5 & 0.4 & 30 \\
\hline
\end{tabular}

\section{Testing procedures}

\subsection{Three-point load test on beams}

A three-point bending testing frame was used for flexural testing. It consist of load cell and LVDT to measure the displacement. Two roller supports of $10 \mathrm{~mm}$ diameter, $100 \mathrm{~mm}$ apart were used during testing. The third roller 
having same diameter and at same distance from first two supports was used to transmit the load ' $\mathrm{P}$ ' on the opposite side of the sample. Loading rate of flexural test was maintained as $50 \pm 10 \mathrm{~N} / \mathrm{s}$ until fracture. Flexural strength is calculated as per IS: 4031 (Part 8) - 1988 by using the following relation.

$$
R=\frac{6 M}{B^{3}}
$$

Where $R$ is flexural strength of the specimen, $M$ is maximum bending moment under central point loading and $B$ is side of the square cross section of the prism.

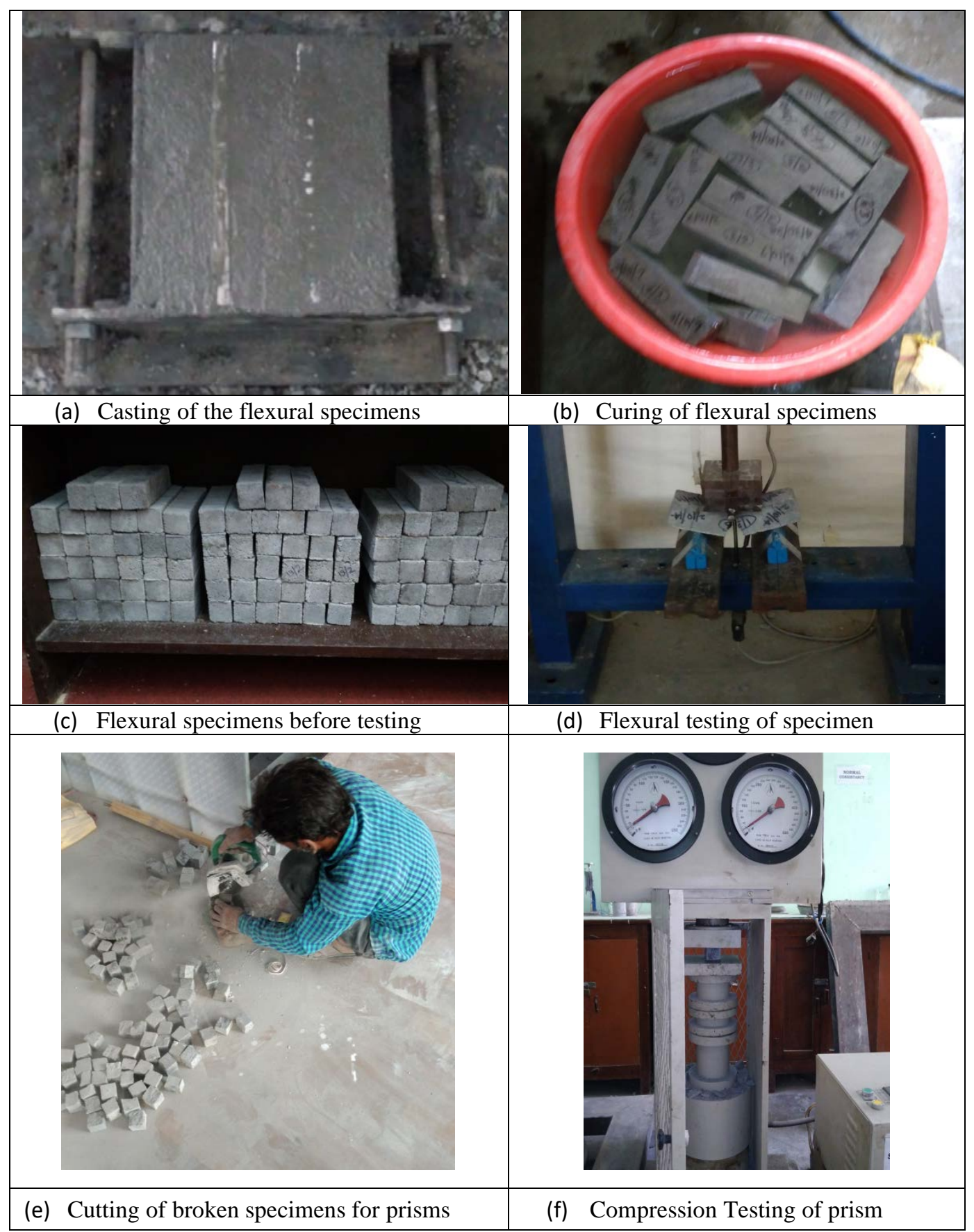

Fig. 3. Various stages of casting and testing

\subsection{Compressive strength test}

After the flexural strength tests, the samples were cut from the ends to the size of cubes $40 \mathrm{~mm} \times 40 \mathrm{~mm} \times 40$ $\mathrm{mm}$ from the uncracked portion of the sample as per IS: 4031 (Part 8) - 1988). Each prism was tested for 
compressive strength test by placing an area $40 \mathrm{~mm} \times 40 \mathrm{~mm}$ between two hard metal plates in compression testing machine of $45 \mathrm{kN}$ capacity provided by AIMIL, Bangalore. The load was applied at the rate of $200 \mathrm{~kg} / \mathrm{cm}^{2} / \mathrm{min}$ over the entire load application until fracture according to standard norm given in IS: 4031 (Part 8) - 1988).

\subsection{Test for density, porosity and water absorption}

These tests were performed on $40 \mathrm{~mm} \times 40 \mathrm{~mm} \times 40 \mathrm{~mm}$ size cubes (derived from the uncracked portion after flexural strength test), before performing compression testing. Density is determined as per IS: 1528 (Part 15) 2007. Dry weight $\left(W_{d}\right)$ of the cubical specimen was determined after oven drying at a temperature of 100 to $110^{\circ} \mathrm{C}$ until reached a constant weight. The samples were then immersed in water for 24 hours. Then, saturated weight $\left(W_{s s d}\right)$ was determined. After immersing the saturated sample in water its apparent submerged weight $\left(W_{w}\right)$ was taken.

Density was determined by using the following formula.

$$
\text { Density }=\frac{W_{d}}{W_{w}-W_{s s d}}
$$

As high porosity decreases the mechanical strength and durability of cementitious materials. Therefore, porosity is an important parameter of study in evaluating the quality and functionality of the cement composites. For calculating the porosity at various curing ages $\left(7,14,28\right.$ days), the water immersed $\left(W_{w}\right)$ and saturated surface dry $\left(W_{s s d}\right)$ weight have been measured. Dried specimen weight $\left(W_{d}\right)$ were measured after kept it in an oven at a temperature of $105 \pm 5^{\circ} \mathrm{C}$. To compute the porosity, the following formula has been employed.

$$
\text { Porosity }=\frac{W_{s s d}-W_{d}}{W_{s s d}-W_{w}} \times 100
$$

where $W_{s s d}$ is the saturated surface dry prisms weight, $W_{w}$ is the weight of prisms taken in the immersed water condition and $W_{d}$ represents the weight of prisms under dried condition. Past studies have successfully employed this method of porosity determination for cementitious composites (Chen et al. 2013).

Water absorption test was performed on mortars cubes with various wt.\% of CNTs at different curing periods (7, 14 and 28 days) after drying at $105^{\circ} \mathrm{C}$ in an oven for one day. After removing from the oven, prisms were allowed to reach room temperature. The prisms were weighed on electronic balance of high accuracy. Their dry weight $\left(W_{d}\right)$ was recorded. These samples were then immersed in water for $24 \mathrm{~h}$ and after removing loose water by paper tower, their weight is again taken and recorded as $W_{s s d}$. The water absorption in \% is calculated by using the following formula.

$$
\text { Water absorption }(\%)=\frac{W_{s s d}-W_{d}}{W_{d}} \times 100
$$

\subsection{Electron microscopy images}

Since carbon nano tubes are not visible with naked eyes, Scanning Electron Microscope (SEM) was employed to study the relations of nanotubes with cement hydration products. To elucidate and substantiate the results from mechanical testing, it was essential to know how the CNTs were holding the hydration products after these samples were tested to failure. With this objective, some selected broken samples after 28 days were subjected to SEM analysis. The SEM was performed at University Sophisticated Instruments Facility (USIF) centre, AMU, Aligarh, India. SEM from JOEL, Japan was used for analysis and interpretation of the variations in the microstructure of the composite matrix.

\section{Results and discussion}

\subsection{Flexural strength}

Fig. 4 depicts the flexural strength of mortar prisms with various wt $\%$ of CNTs at 7, 14 and 28 days of immersed water curing. This strength enhancement follows an uptrend up to $0.3 \mathrm{wt} \% \mathrm{CNT}$ content beyond which a falling trend was observed. In few cases, the inclusion of CNTs indicate a decrease in strength compared to control samples. The improvement in strength may be attributed to the use of CNT which behaves not only as filler to improve microstructure but also as an activator to promote high chemical reactivity due to greater surface area of CNTs. Typically, CNTs reduce the number of fine pores within C-S-H gel, and fortify the nano structure of cementitious composites. Further, reduction in strength for CNT prisms in excess of $0.3 \%$ is primarily due to two reasons. Firstly, less water remains available in such prisms as more water stick to CNT surfaces and ultimately obstructs proper hydration. Secondly, more nano tubes get agglomerated causing water to entrap within clumped CNTs resulting insufficient hydration of cement. The highest increase in flexural strength (33\%) was shown at 7 
days for $0.3 \%$ CNT prisms when compared to control prisms. The increase in flexural strength at 28 days for the prisms with $0.3 \%$ CNT was found to be $25 \%$. A higher increase in strength at early ages indicates that presence of CNTs initiates quick hydration at early ages (0-7 days). The reason behind quick hydration at early ages is that inclusion of CNTs in the matrix increased the hydration reaction of $\mathrm{C}_{3} \mathrm{~S}$. The morphology of both $\mathrm{C}_{3} \mathrm{~S}$ and $\mathrm{C}_{3} \mathrm{~A}$ hydration compounds were found to be affected by the addition of nano tubes [12]. The nano tubes seemed to be acted as nucleating sites for the $\mathrm{C}_{3} \mathrm{~S}$ hydration compounds, wherein the CNTs becoming quickly coated with C-S$\mathrm{H}$ gel. The formation of $\mathrm{Ca}(\mathrm{OH})_{2}$ during the initial period of hydration increases. Thus, heat of hydration increased leading to higher strength at early ages. It is also observed that above $0.3 \%$ CNT, the strength shows a decreasing trend compared to control prisms at respective curing periods. Therefore, the optimum concentration of CNTs is found to be $0.3 \mathrm{wt} . \%$ of cement for obtaining high strength mortars.

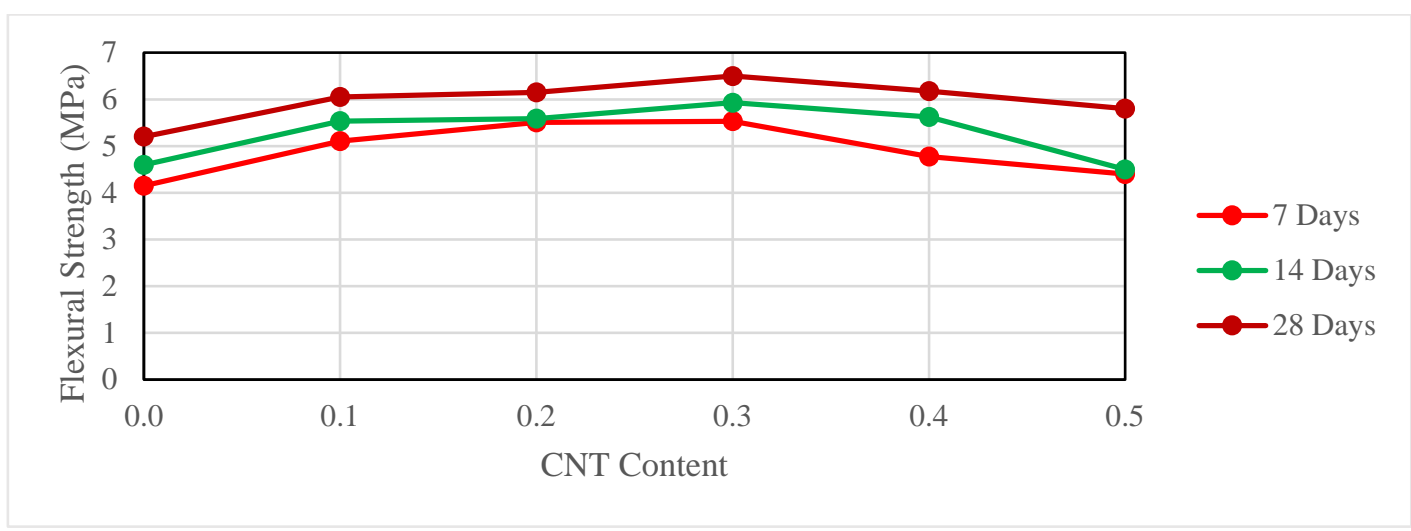

Fig. 4. Effect of increasing CNT content in the mix on flexural strength of prisms

Deviation in the outcomes of the same mix of a sample was observed in few instances even though each sample of a lot are alike and prepared from the same mix proportions. Uniform distribution of the CNTs by sonication process does not have a guarantee for its uniform distribution within the matrix, hence the stress variation in the flexural prisms will be non-uniform that leads to variable flexural behaviour of the samples. Contrary to nonuniform dispersion of CNTs in the matrix, formation of weak hydration products could be the reason behind flexural strength reduction in some prisms in relation to control ones.

\subsection{Compressive strength}

Compressive strength of mortar prisms for various wt\% of CNTs at different ages are reported in Table. 4. It is found that at all curing periods, compressive strength increases up to $0.3 \mathrm{wt} \% \mathrm{CNTs}$. The maximum 7 days strength under compression was found for composites with $0.3 \%$ CNT prisms. The maximum increase in compressive strength was about $21 \%$ than the control prisms. Increase in compressive strength after 14 days of curing was about 23\%. At 28 days, a lesser increase in strength (19\%) was obtained compared to control prisms. The mechanism for increase in strength at low CNT contents is same to the strength enhancement mechanism as discussed in the previous section. Beyond 0.3\% CNT addition, a falling trend is observed in compressive strength. As amount of CNT was increased, more aqueous solution was required for proper sonication and additional water stick to the CNT surface due to larger surface area of CNTs. Consequently strength reduction is observed due to less workability. Also higher dosage rate of CNT has greater tendency to agglomerate and, therefore, uniform dispersion is difficult to achieve. In turn, CNT fail to fill nano space within cement grains which is very important for achieving proper reinforcement behaviour. So there exists an optimum concentration of CNT that could result in desired properties of the cementitious prisms. Manzur et al. [23] obtained similar results in their study for finding optimum percentage of CNTs in mortars.

Table 4. Compressive strength of test prisms at various curing ages

\begin{tabular}{llll}
\hline $\begin{array}{l}\text { Specimen } \\
\text { constitution }\end{array}$ & \multicolumn{3}{c}{ Compressive strength (MPa) } \\
\cline { 2 - 4 } & $\mathbf{7}$ days & $\mathbf{1 4}$ days & $\mathbf{2 8}$ days \\
\hline Control specimen & 20.10 & 22.80 & 30.00 \\
$0.1 \%$ CNT & 22.00 & 25.19 & 32.50 \\
$0.2 \%$ CNT & 22.92 & 27.08 & 33.90 \\
$0.3 \%$ CNT & 24.26 & 28.05 & 35.63 \\
$0.4 \%$ CNT & 23.65 & 26.30 & 34.60 \\
$0.5 \%$ CNT & 22.40 & 25.20 & 33.00 \\
\hline
\end{tabular}




\subsection{Test for density, porosity and water absorption}

The inclusion of nano tubes in the cement mortar results an increase in density from 7 to 28 days (see Table. 5). At all curing ages, quite identical results were found for density enhancement. Composites with $0.3 \%$ CNTs show better density results, an increament of $5-6 \%$ as compared to control prisms. The increase in density can be attributed to the fact that small voids and pores in the cementitious matrix are effectively filled by CNTs leading to higher density of the composites. At higher dosage rate, CNT has greater tendency to agglomerate, therefore, uniform dispersion is difficult to achieve. In turn, CNT fails to fill nano space within cement grains and consequently density will decrease. Therefore, optimum content of CNTs for obtaining denser composites is found to be 0.3 wt.\%.

Table 5. Density of test prisms at various curing ages

\begin{tabular}{llll}
\hline $\begin{array}{l}\text { Specimen } \\
\text { constitution }\end{array}$ & \multicolumn{3}{c}{ Density $\mathbf{( g / \mathbf { c m } ^ { \mathbf { 3 } } )}$} \\
\cline { 2 - 4 } & $\mathbf{7}$ days & $\mathbf{1 4}$ days & $\mathbf{2 8}$ days \\
\hline Control specimen & 2.10 & 2.12 & 2.15 \\
$0.1 \%$ CNT & 2.14 & 2.15 & 2.17 \\
$0.2 \%$ CNT & 2.20 & 2.22 & 2.25 \\
$0.3 \%$ CNT & 2.22 & 2.24 & 2.26 \\
$0.4 \%$ CNT & 2.17 & 2.19 & 2.21 \\
$0.5 \%$ CNT & 2.14 & 2.16 & 2.20 \\
\hline
\end{tabular}

Table. 6 show a decreasing trend in apparent porosity of samples at lower percentages of CNTs (upto 0.3\%) at all ages under investigation. At higher dosage rates, a reverse trend is observed. The possible reason for this behaviour is that at low concentrations, CNTs can possibly fill between the pores of hydration compounds. Consequently, the apparent porosity is decreasing due to denser microstructure in comparison to control prisms. A $25 \%$ decrease in apparent porosity is observed at 28 days for $0.3 \mathrm{wt} . \%$ CNTs.

Table 6. Apparent porosity of test prisms at various curing ages

\begin{tabular}{llll}
\hline $\begin{array}{l}\text { Specimen } \\
\text { constitution }\end{array}$ & \multicolumn{3}{c}{ Apparent porosity (\%) } \\
\cline { 2 - 4 } Control specimen & 15.01 & $\mathbf{1 4}$ days & $\mathbf{2 8}$ days \\
$0.1 \%$ CNT & 14.66 & 14.46 & 14.01 \\
$0.2 \%$ CNT & 12.54 & 14.14 & 13.27 \\
$0.3 \%$ CNT & 11.54 & 12.12 & 11.50 \\
$0.4 \%$ CNT & 12.81 & 11.14 & 10.56 \\
$0.5 \%$ CNT & 13.86 & 12.30 & 11.48 \\
\hline
\end{tabular}

Water absorption results for various curing periods (7, 14 and 28 days) with various wt.\% of CNTs are given in Table. 7. It shows minimum water absorption property of mortars when the wt.\% of CNTs used is $0.3 \%$. At 7, 14 and 28 days, water absorption results were found to decrease by about $18-19 \%$ for specimen with 0.2 wt.\% CNTs. These values are further reduced by $21 \%, 24 \%$ and $26 \%$ for 0.3 wt. $\%$ CNTs at respective ages. When the CNT percentage is less, a lesser decrease in water absorption values were obtained. The possible reason for such phenomenon is that at low concentrations of CNTs, the small voids and pores are partially filled by hydration products and hence gave higher absorption values. Although, agglomeration at high concentration (beyond 0.3\%) affect uniform distribution of the CNTs in the cement matrix. Hence, these unfilled voids and pores aid in water absorption. Therefore, best performing CNT percentage for lowest water absorption values is found to be $0.3 \mathrm{wt} . \%$.

Table 7. Water absorption of test prisms at various curing ages

\begin{tabular}{llll}
\hline $\begin{array}{l}\text { Specimen } \\
\text { constitution }\end{array}$ & \multicolumn{3}{c}{ Water absorption (wt. \%) } \\
\cline { 2 - 4 } & $\mathbf{7}$ days & $\mathbf{1 4}$ days & $\mathbf{2 8}$ days \\
\hline Control specimen & 7.17 & 7.03 & 6.75 \\
$0.1 \%$ CNT & 6.99 & 6.69 & 6.25 \\
$0.2 \%$ CNT & 5.90 & 5.32 & 5.44 \\
$0.3 \%$ CNT & 5.63 & 5.75 & 5.01 \\
$0.4 \%$ CNT & 6.16 & 5.80 & 5.51 \\
$0.5 \%$ CNT & 6.32 & 6.12 & 6.00 \\
\hline
\end{tabular}


Hence, from the stated outcome for the CNT prisms, one can see that in majority of the cases, the apparent porosity and water absorption decreased from 7 to 28 days (see Table. 5 and 6). The reverse is observed for the density (see Table. 4). In general, this trend is more likely with prisms upto $0.3 \%$ CNT concentration. Beyond this limit, increase in CNT concentration showed increase in corresponding values. Although this observation is vital from economic aspect; the lesser the percentage of CNTs in the matrix the lesser the cost of CNT composites, for desirable mechanical properties one may ensure uniform distribution of nano tubes in the composite matrix.

\subsection{Load deflection curves}

Based on the three point flexural test, optimum percentage of CNTs was evaluated for reinforcing plain mortar prisms. Five dosage rates of $0.1 \%, 0.2 \%, 0.3 \%, 0.4 \%$ and $0.5 \%$ were used to prepare the prisms. Testing were performed at the age of 7,14 and 28 days. Load deflection data and ultimate load taken by prisms were recorded. The optimum concentration of CNT by wt.\% of cement was determined on the basis of maximum load carrying capacity of the prisms. For comparative study, comparisons were made with the results of plain mortar prisms. The ultimate load carrying capacity of various MWCNT reinforced flexural specimens at different curing periods is provided in Table 8. The ultimate load followed a rising trend up to $0.3 \mathrm{wt}$. \% CNT beams for all curing periods. The mechanism of enhancement in load-deflection criteria is similar to the flexural strength enhancement mechanism as discussed before. These CNTs react with $\mathrm{Ca}(\mathrm{OH})_{2}$ resulting in matrix densification, thus reducing the porosity. Therefore, under load application on prisms, a maximum load-deflection was obtained for $0.3 \% \mathrm{CNT}$ composites at various curing periods.

Table 8. Test results for MWCNT reinforced flexural specimens subjected to the three-point loading test: Ultimate load and maximum deflection.

\begin{tabular}{lllll}
\hline S.No & Specimen reference & Age of testing (days) & Ultimate load (kN) & Maximum deformation (mm) \\
\hline 1 & $0.3 \%$ MWCNT & 7 & 2.45 & 0.23 \\
2 & $0.3 \%$ MWCNT & 14 & 2.88 & 0.25 \\
3 & $0.3 \%$ MWCNT & 28 & 3.14 & 0.26 \\
\hline
\end{tabular}

Fig.5 shows load deflection curves for few CNT flexural beams. Based on the observation, one can say that behaviour of the material is elastic right upto the failure.

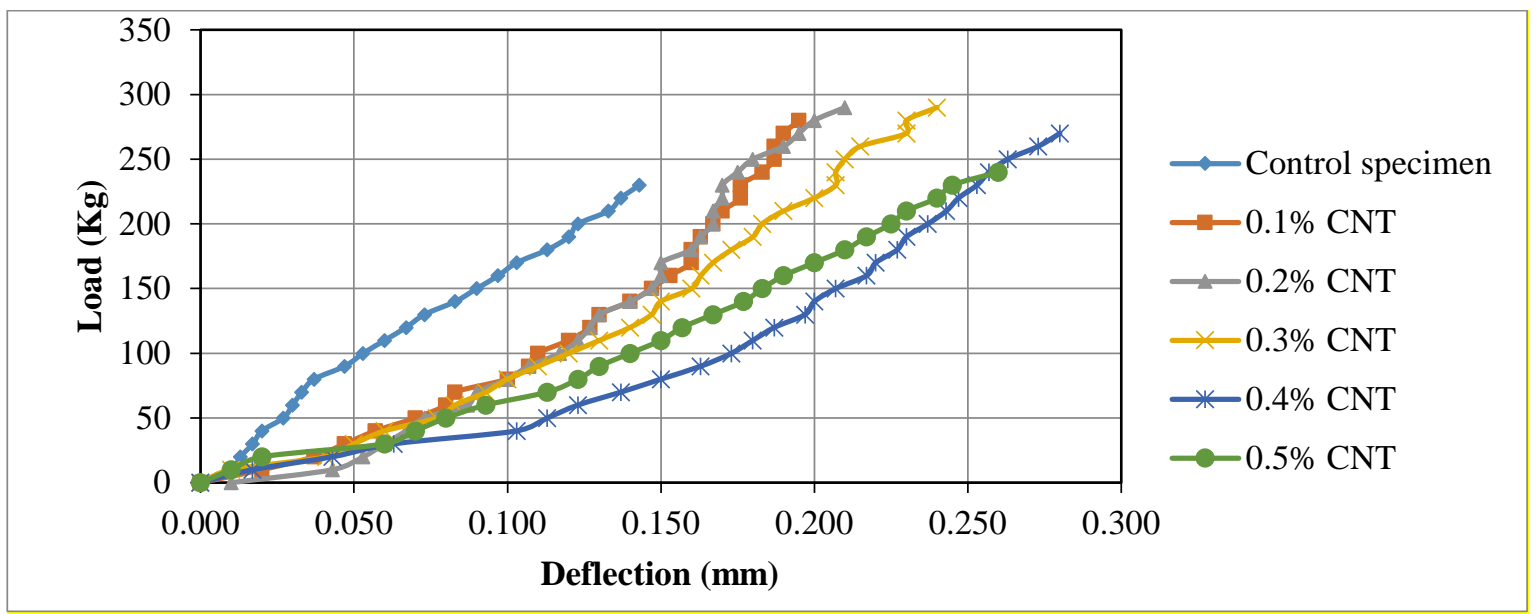

Fig. 5. Load deflection curves for few CNT beams at 14 days

Hence, from the stated outcome for the CNT specimens, one can see that if CNTs were added into any matrix with proper dispersion, the benefits of using them can be obtained. Contrary, the benefits of using CNTs in concrete or mortar will be limited and defects could be obtained. Anyway, the benefits of using CNTs include accelerating cement hydration, stronger and lighter structure composites, improving mechanical strength, controlling crack propagation, reducing porosity and water absorption. Thus, CNTs extend service life of structures.

\subsection{Electron microscopy images}

The main objective of performing SEM analysis was to comprehend how the CNTs are holding the hydration products after testing of CNT prisms. The broken samples post mechanical testing after 28 days were crushed to a fine powder and taken to the USIF centre at AMU. The broken samples were subjected to SEM analysis under various magnifications, ranging from $3000 \times$ to $2000 \times$. Fig. 6 (a) - (d) show selected SEM images of the samples. 
The image of control prisms in Fig. 6 (a) shows several voids and cracks in their microstructure. Fig. 6 (d) shows how the nano tubes were distributed in the cement matrix. Agglomeration of nano tubes seen in the image specify inadequate dispersion of CNTs in the matrix. Some agglomerated CNTs were shown entangled with each other without any connection to the matrix. Improper dispersion of nano tubes, as shown in Fig. 6 (d), might be responsible for hindering the bonding between the hydration products. From obtained mechanical testing results in earlier sections, this seems to be the justification that CNTs at higher dosage rates (0.4\%-0.5\%) did not actively take part in holding the matrix and ultimately improving its properties. For example, mechanical strengths tests showed strength enhancement of CNT composites, when the CNT percentage was upto $0.3 \%$. However, flexural and compressive strength of $0.4 \%$ and $0.5 \%$ CNT prisms showed degradation in strength to be less than that of $0.3 \%$ CNT prisms. It shows that when the concentration of nano tubes was less, good dispersion was accomplished, causing improvement in strength. Fig. 6 (b) shows some CNTs bridging a micro crack as well as pull out, indicating that CNT was assisting to hold the cementitious matrix at low concentrations. Fig. 6 (c) shows both CNTs and small needle like ettringite formations, which could describe the degradation in mechanical properties in samples with higher content of CNTs. From SEM micrographs, it was tough to distinguish any sort of chemical bonding between hydration products and CNTs and it should be investigated in future study by using TEM or EDS technique.

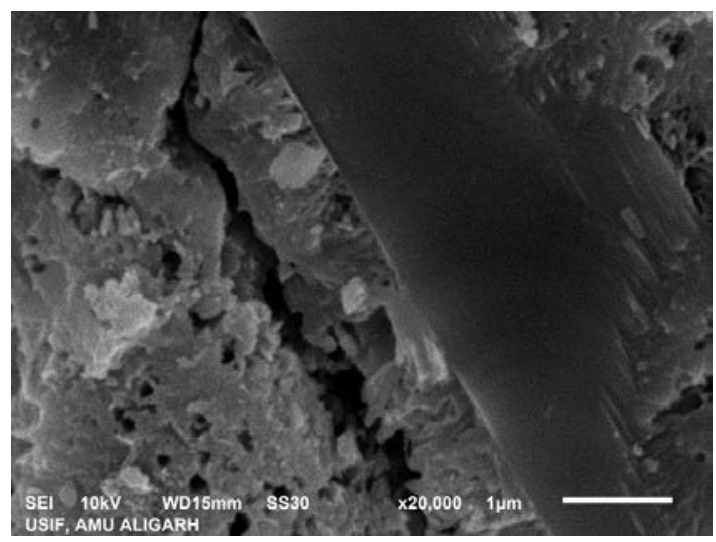

(a)

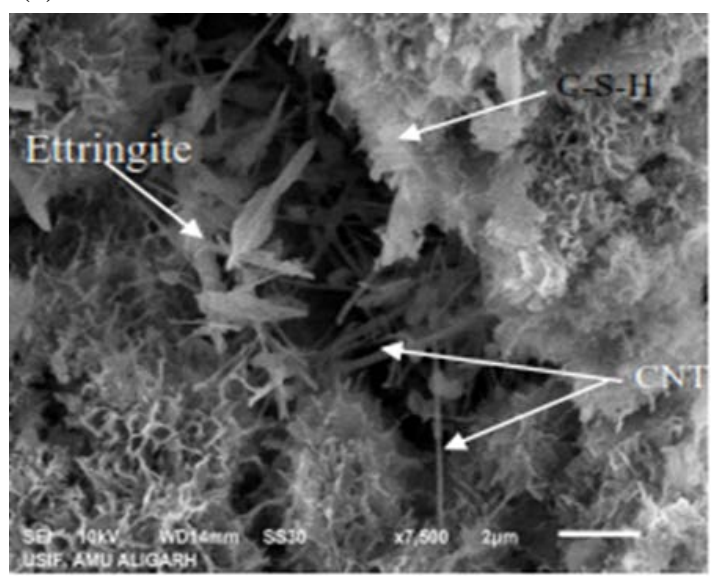

(c)

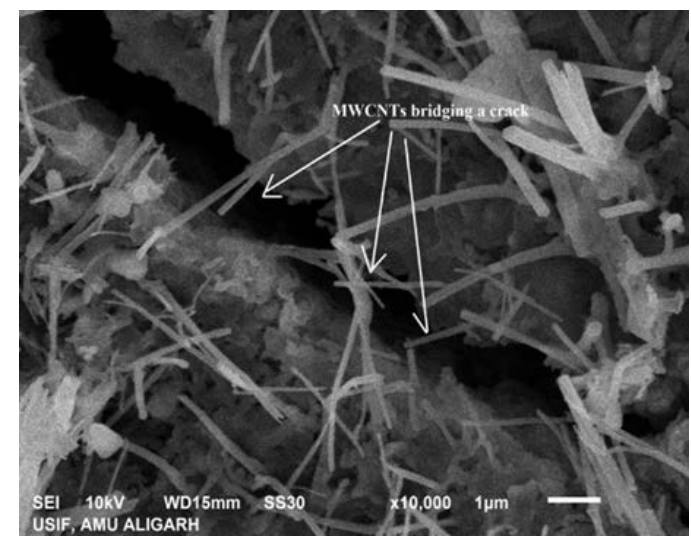

(b)

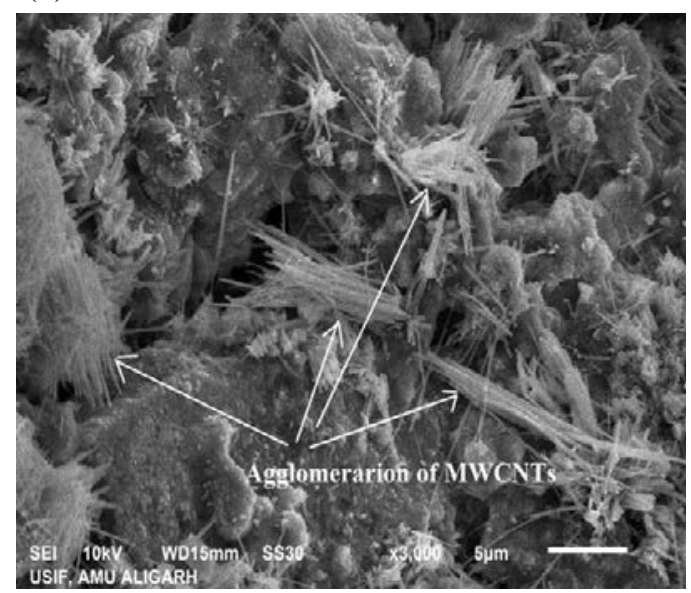

(d)

Fig. 6. (a) SEM micrographs of mortars without CNTs, (b) with 0.3 (c) 0.4 and (d) 0.5 wt.\% of CNTs at 28 days

\section{Conclusions}

From the various studies performed on nano composites, the following conclusions are drawn:

1) Larger increase in flexural and compressive strength was observed in prisms having $0.3 \%$ CNT content by weight of cement. The maximum increase in the mentioned strengths with respect to the control samples at 7 days was $33 \%$ and $21 \%$, respectively. At 28 days, the same values for strength enhancement were found to be $25 \%$ and $19 \%$, respectively. CNT composites with nano tube content in excess of $0.3 \%$ shows a decreasing trend in strength. It is also observed that CNT composites produced higher strengths as compared to control composites which can 
be due to high aspect ratio of CNTs which makes them more effective as reinforcement due to their larger interaction (higher specific surface area) with the cementitious matrix.

2) The addition of CNTs in the matrix increased mechanical strength due to filling the pores between hydration products, bridging cracks and pores, and acting as nucleating agents for CSH gel. On the other hand, high concentration of CNTs are not beneficial and resulted in agglomeration. Consequently, the mechanical strength decreased.

3) It was found from the study that nano tube admixed cement composites hardened relatively rapidly as compared to normal cement mortar. A higher increase in strength at early ages (0-7 days) verifies the fact that hydration process accelerates in the presence of CNTs. The reason behind accelerated hydration may be attributed to increased formation of $\mathrm{Ca}(\mathrm{OH})_{2}$. Thus heat of hydration increased leading to higher strength at early ages.

4) The inclusion of CNTs in the cement matrix lowers the porosity and water absorption capacity due to filling the pores between hydration products and filling the voids. These are the main parameters that affecting durability and service life of the structural concrete or mortar. Thus, CNTs extend service life of the structures.

5) Although, useful qualitative comparisons can be obtained from the SEM characterizations, additional microstructural characterization using TEM or EDS are needed to fully understand the reasons for the enhancement or degradation of the mechanical properties of CNT composites.

6) Further work in this area involves the development of new hybrid composites using materials both at nano and micro level that could address both nano/micro level aspects of structural concrete/mortar. Accordingly, the application of different nano materials like nano silica, nano alumina at nano level and silica fume, fly ash at micro level with conventional concrete could also be effectively used for clean and sustainable development.

\section{References}

[1] Wang J, Fang Z, Gu A, Xu L, Liu F. Effect of amino-functionalization of multi-walled carbon nanotubes on the dispersion with epoxy resin matrix. Journal of Applied Polymer Science. 2006;100(1):97-104.

[2] Marrs B, Andrews R, Pienkowski D. Multiwall carbon nanotubes enhance the fatigue performance of physiologically maintained methyl methacrylate-styrene copolymer. Carbon. 2007;45(10):2098-2104.

[3] Manzur T, Yazdani N. Effect of different parameters on properties of multiwalled carbon nanotube-reinforced cement composites. Arabian Journal for Science and Engineering. 2016;41(12):4835-4845.

[4] Salvetat-Delmotte JP, Rubio A. Mechanical properties of carbon nanotubes: a fiber digest for beginners. Carbon. 2002;40(10):1729-1734.

[5] Aiu M. The Chemistry and Physics of Nano-Cement, Loyola Marymount University, NSF-REU, University of Delaware, 2006.

[6] Li GY, Wang PM, Zhao X. Mechanical behavior and microstructure of cement composites incorporating surface-treated multi-walled carbon nanotubes. Carbon. 2005;43(6):1239-1245.

[7] Al-Rub RK, Ashour AI, Tyson BM. On the aspect ratio effect of multi-walled carbon nanotube reinforcements on the mechanical properties of cementitious nanocomposites. Construction and Building Materials. 2012;35:647-655.

[8] Hallad SA, Banapurmath NR, Hunashyal AM, Shettar AS, Ayachit NH, Mruthunjaya AK, Lohit RB, Uttur M. Experimental investigation for graphene and carbon fibre in polymer-based matrix for structural applications. Journal of Applied Research and Technology. 2017;15(3):297-302.

[9] Manzur T, Yazdani N. Strength enhancement of cement mortar with carbon nanotubes: early results and potential. Transportation Research Record: Journal of the Transportation Research Board. 2010;2142(1):102108.

[10] Yazdani N, Mohanam V. Carbon nano-tube and nano-fiber in cement mortar: effect of dosage rate and watercement ratio. International Journal of Material Science. 2014;4(2):45.

[11] Mohsen MO, Taha R, Taqa AA, Shaat A. Optimum carbon nanotubes' content for improving flexural and compressive strength of cement paste. Construction and Building Materials. 2017;150:395-403.

[12] Rashad AM. Effect of carbon nanotubes (CNTs) on the properties of traditional cementitious materials. Construction and Building Materials. 2017;153:81-101.

[13] Jeevanagoudar YV, Krishna RH, Gowda R, Preetham R, Prabhakara R. Improved mechanical properties and piezoresistive sensitivity evaluation of MWCNTs reinforced cement mortars. Construction and Building Materials. 2017;144:188-194.

[14] Sadrmomtazi A, Tahmouresi B, Amooie M. Permeability and mechanical properties of binary and ternary cementitious mixtures. Advances in Concrete Construction. 2017;5(5):423-436.

[15] Akcay B, Sengul C, ali Tasdemir M. Fracture behavior and pore structure of concrete with metakaolin. Advances in Concrete Construction. 2016;4(2):71-88.

[16]Ashok M, Parande AK, Jayabalan P. Strength and durability study on cement mortar containing nano materials. Advances in Nano Research. 2017;5(2):99-111. 
[17] Lee HS, Balasubramanian B, Gopalakrishna GV, Kwon SJ, Karthick SP, Saraswathy V. Durability performance of CNT and nanosilica admixed cement mortar. Construction and Building Materials. 2018;159:463-472.

[18] Carriço A, Bogas JA, Hawreen A, Guedes M. Durability of multi-walled carbon nanotube reinforced concrete. Construction and Building Materials. 2018;164:121-133.

[19] Li LG, Zhu J, Huang ZH, Kwan AK, Li LJ. Combined effects of micro-silica and nano-silica on durability of mortar. Construction and Building Materials. 2017;157:337-347.

[20] Chen X, Wu S, Zhou J. Influence of porosity on compressive and tensile strength of cement mortar. Construction and Building Materials. 2013;40:869-874.

[21] Paul SC, van Rooyen AS, van Zijl GP, Petrik LF. Properties of cement-based composites using nanoparticles: A comprehensive review. Construction and Building Materials. 2018;189:1019-1034.

[22] Shi T, Li Z, Guo J, Gong H, Gu C. Research progress on CNTs/CNFs-modified cement-based composites-A review. Construction and Building Materials. 2019;202:290-307.

[23] Manzur T, Yazdani N, Emon M, Bashar A. Effect of carbon nanotube size on compressive strengths of nanotube reinforced cementitious composites. Journal of Materials. 2014;2014:1-8.

(C) 2020 by the author(s). This work is licensed under a Creative Commons Attribution 4.0 International License (http://creativecommons.org/licenses/by/4.0/). Authors retain copyright of their work, with first publication rights granted to Tech Reviews Ltd. 